\title{
The National School Fruit Scheme produces short-term but not longer-term increases in fruit consumption in primary school children
}

\author{
Lesley Wells and Michael Nelson* \\ Department of Nutrition and Dietetics, King's College London, 150 Stamford Street, London SE1 9NN, UK \\ (Received 22 December 2003 - Revised 4 December 2004 - Accepted 7 December 2004)
}

\begin{abstract}
The National School Fruit Scheme (NSFS) provides one free piece of fruit each school day to children, aged 4 to 6 years, attending state schools in England. The aims of the present study were to determine if NSFS was associated with a higher fruit consumption in infant school children (4-6 years old), and to assess whether fruit consumption was higher in junior school children (7-8 years old) who had received free fruit as infants compared with those who had not. The present cross-sectional study involved seventeen schools, eight in the NSFS (study schools) and nine not in the NSFS (control schools). Study and control schools were selected in areas of similar levels of deprivation. All schools were on the outskirts of London in Southeast England. A retrospective $24 \mathrm{~h}$ food tick list was given to each pupil in Reception to Year 4 to take home for their parents to complete and return. Response rate was $51 \%$. Median total fruit consumption (excluding fruit juice) in infants receiving free fruit was $117 \mathrm{~g} / \mathrm{d}$ compared with $67 \mathrm{~g} / \mathrm{d}$ in infants not receiving free fruit $(P<0.001)$. Median consumption in juniors who had received free fruit at school as infants did not differ from those who had not (83 $\mathrm{g} / \mathrm{d} v$. $86 \mathrm{~g} / \mathrm{d}$ ). The NSFS has increased fruit consumption in infant school children. It does not appear to have longer-term effects in junior school children. If the scheme is to affect dietary habits and improve health in the long term, further interventions will be needed.
\end{abstract}

National School Fruit Scheme: Fruit consumption: School children: England

There is evidence to suggest that the consumption of fruit and vegetables is probably protective against CHD and some types of cancer (Williams \& Marmot, 1997; World Health Organization, 2003; Nishida et al. 2004). Current advice is to consume five portions of fruit and vegetables $(400 \mathrm{~g})$ daily. Amongst UK children aged 4 to 10 years, consumption is $176 \mathrm{~g} / \mathrm{d}$ (Gregory \& Lowe, 2000), just over two $80 \mathrm{~g}$ portions daily and well below the recommended level. The UK Government has developed a '5-a-day' programme to increase fruit and vegetable consumption, especially among children and people on a low income. The National School Fruit Scheme (NSFS) is part of this programme (Department of Health, 2003a). It provides one free piece of fresh fruit (or vegetable) to infant school pupils aged 4-6 years each school day. During 2002-2004, £42 million from the New Opportunities Fund (2005) was invested in the NSFS. Schemes in other European countries have relied on subscriptions to provide fruit and vegetables to those who will pay, rather than free fruit for all (Eriksen et al. 2003; Norwegian Directorate of Health and Social Affairs, 2004).

The aim of the NSFS is to increase fruit consumption in the children receiving school fruit. This assumes that parents will not reduce the amount of fruit being provided at home. It also aims to create a culture of fruit eating, so that when infant school pupils move on to junior school (pupils aged 7-10 years) they will continue to have increased fruit consumption.
A pilot scheme was carried out from Autumn 2000 to September 2002 in selected schools in England, in anticipation of a phased implementation nationally to be completed by 2004 . Thus there was an opportunity in the Summer term of 2003 to make two comparisons of fruit consumption: (i) between infant school pupils attending schools in the NSFS pilot or early phases of the main scheme and pupils attending schools not yet in the scheme; (ii) between junior school pupils who had participated in the pilot scheme as infant school pupils and those who had not. The expectation was that fruit consumption would be higher amongst the infant and junior school pupils who attended schools in the NSFS compared with pupils from schools not in the scheme.

To date, evaluation of the NSFS has been carried out only in terms of whether the fruit got from the farm to the child's hand (Department of Health, 2003b), not in terms of total fruit consumption. The New Opportunities Fund financed an evaluation which started in Autumn 2003.

\section{Method \\ Sampling}

Schools that had joined the pilot of the NSFS in February 2001 and continued in the main scheme in October 2002 were 
eligible for selection. They provided a sample of infant school pupils aged 4-6 years currently receiving free fruit and a sample of junior school pupils aged 7-8 years who had received free fruit when they were infants. (For the sake of brevity, the terms 'infants' and 'infant pupils' are used to denote pupils typically aged 4-6 years attending infant schools. Classes in infant schools include Reception, Year 1 and Year 2. The terms 'juniors' and 'junior pupils' are used to denote pupils typically aged 7-8 years attending junior schools. Junior schools include Year 3 through to Year 6. In the present study, only children in the first two years of junior school (Years 3 and 4) who would have been in primary school during the period of introduction of the pilot school fruit scheme have been included.) Schools that joined the main scheme in October 2002 were also eligible. They provided samples of infant school pupils receiving free fruit and junior school pupils who had not received free fruit. Other primary schools not in the NSFS pilot or main scheme provided a control group.

Three areas of low-to-middle income on the outskirts of London in Southeast England were chosen. Two had been in the pilot scheme and one was in the main scheme. In order to focus on children from low-income households, two criteria were used to select schools. First, electoral wards in the bottom $20 \%$ of the distribution of IMD2000 (Index of Multiple Deprivation; Department of Transport, 2000) were identified. There were nineteen primary schools (infant, junior, or combined infant and junior schools) in these areas. Second, schools that had a minimum of $15 \%$ of pupils eligible for free school meals were selected. Of the nineteen schools in the poorest areas, eight schools had between 15 and $40 \%$ of pupils receiving free school meals. These included six primary schools (with both infant and junior pupils), and one infant and one junior school (with separate head teachers) on the same site. All eight schools (the 'study schools') agreed to participate.

Three further areas were then identified that were near to the study school areas, had similar socio-economic character and were not in the NSFS pilot or main scheme. Twenty-one primary schools were identified in wards in the bottom $20 \%$ of the distribution of IMD2000 (Department of Transport, 2000), and fifteen of these provided free school meals to between 15 and $40 \%$ of pupils. Nine of these (the 'control schools') agreed to participate, consisting of four primary schools, two infant and junior schools (with separate head teachers) on the same site, and one junior only school. Six schools in these areas declined to participate.

Information on school participation in the NSFS, percentage of pupils receiving free school meals and percentage of white British pupils were obtained from the local education authorities.

The study design was cross-sectional. Two sets of comparisons were made:

1. Fruit consumption in infant pupils receiving free fruit compared with pupils not receiving free fruit.

2. Junior pupils who had received free fruit as infants compared with junior pupils who had not received free fruit as infants.

Comparisons were made at both the school level and level of the individual (to assess distributions of the number of portions of fruit consumed and the median grams of fruit consumption per child daily).

\section{Questionnaire}

A questionnaire was developed, which included a $24 \mathrm{~h}$ food tick list, food frequency questions, food attitude questions, questions about the NSFS and personal data. It was designed to be quick and simple to answer, and was completed by parents on behalf of their child.

A tick list of foods was adapted from the Food Assessment in Schools Tool (FAST) questionnaire validated by Adamson et al. (2003). FAST was designed to record all food and drink consumed over $4 \mathrm{~d}$ and to use observers to record food intake during school time. The present study focused on total fruit consumption (including fresh, tinned, frozen and fruit juice), so the number of foods on the tick list was reduced from that on FAST to provide a $24 \mathrm{~h}$ record of fruit and fruit juice consumed on the day of completion. The tick list was divided into time slots to aid the recollection of food consumption. Consumption was reported by parents. Portion size and weight were not reported.

A short food frequency questionnaire was included to provide internal validation of the tick list. Questions were asked about the child's usual frequency of consumption of fruits and vegetables (based on Thompson et al. 1999) and other food groups (to avoid over-focusing on fruit).

Questions concerning factors influencing parents in their purchase of fruit were based on questions in the 5 A Day Consumption and Evaluation Tool (FACET) questionnaire (Department of Health, 2003c). The FACET questionnaire has been used to evaluate local 5-a-day initiatives.

Each school was provided with a sufficient number of questionnaires to hand out to every pupil in Reception through Year 4. Questionnaires were distributed in large A4 $(22 \mathrm{~cm} \times 32 \mathrm{~cm})$ envelopes that also contained a study information sheet and an A5 $(16 \mathrm{~cm} \times 22 \mathrm{~cm})$ envelope in which to return the questionnaire to the school. On a day agreed with the school, each pupil present was given an A4 envelope to take home. Completed questionnaires were collected from the schools $9 \mathrm{~d}$ later. There was no follow-up due to time constraints.

\section{Data analysis and statistics}

Questionnaire results were analysed using the Statistical Package for the Social Sciences, version 11.0.1 (SPSS Inc., Chicago, IL, USA). Median portion sizes were calculated from National Diet and Nutrition Survey data for 4-6-year-olds and 7-10-yearolds (Gregory \& Lowe, 2000) and were used to convert estimates of frequencies of fruit consumption to $\mathrm{g} / \mathrm{d}$.

Fruit consumption (number of portions/d and g/d) was not normally distributed (Kolmogorov-Smirnov test, $P<0 \cdot 001$ ). Transformation of the variables using natural $\log$, square root, inverse and inverse square root at both individual and school level failed to generate distributions that could have been derived from normally distributed populations. Comparisons of frequency of consumption (number of portions/d) and median $\mathrm{g}$ fruit/d between pupils receiving or not receiving free fruit and between infant or junior school pupils were therefore assessed using the Mann-Whitney test. Comparisons of the cumulative percentages of pupils according to the number portions of fruit consumed daily were compared using the Kolmogorov-Smirnov two-sample test. Analyses were carried out at both the school and individual level. 


\section{Results}

\section{Sample characteristics and response rate}

There were no statistically significant differences between the study and control schools in terms of the selection parameters. The mean IMD score for the wards in which the schools were located was 38.5 (SD 2.6) and 37.6 (SD 2.7), respectively. Mean percentage of free school meals was 30.4 (SD 6.0) and 25.5 (SD 5.3), respectively, ranging from $16 \cdot 9$ to $37 \cdot 7$. Mean percentage of pupils with white British background was 56.5 (SD 15.5) and $81 \cdot 1$ (SD 11.1), respectively. There was a similar distribution of boys and girls, and of pupils in each of the school year groups, in the study and control schools.

Of 2980 questionnaires distributed to the parents, 1517 (51\%) were completed and returned, $46 \%$ in the study schools and $59 \%$ in the control schools. For 25 pupils (1.6\%), parents reported between eleven and thirty-two portions of fruit consumed in $1 \mathrm{~d}$. It was likely that these parents had misinterpreted the questions and that the data did not reflect true consumption levels. Data from these questionnaires were therefore excluded from the analysis.

\section{Frequency of fruit consumption}

There were no statistically significant differences in the median frequency of consumption between the tick list and the food frequency questionnaire data. All results on consumption are therefore based on the tick list.

Fig. 1 shows the cumulative percentage of pupils according to the number of portions of fruit (including fruit juice) consumed daily in 1492 primary school pupils in Southeast England, according to year group (infant, Fig. 1(a) or junior, Fig. 1(b)) and whether or not they had received free school fruit. The values show consumption on all days of the week, not just school days. Amongst the infant pupils eligible to receive free school fruit, only $12 \%$ reported not having consumed fruit on the day of the survey, compared with $22 \%$ in the group not receiving free fruit. Comparison of the two cumulative distributions based on the Kolmogorov-Smirnov two-sample test showed statistically significant differences between the distributions in infants $(P=0.020)$ but not in juniors $(P=0.962)$. The median value for both groups of infants (who received or did not receive free fruit) was 2, but the Mann-Whitney test (which assesses differences in the distribution of consumption between the two groups and takes the many tied values into account) yielded a statistically significant difference $(P=0 \cdot 000)$. The difference was most apparent at the 40th and 70th centiles: median portions/d were 2 and 3, respectively, amongst infants receiving fruit and 1 and 2, respectively, in those not receiving fruit. Analysis at the school level (the medians were also 2 in both groups of schools) showed a borderline difference $(P=0.053)$ even with the very small numbers in the sample of infant schools (seven NSFS schools and six control schools). There were no differences in total fruit consumption between the junior school pupils who had had free fruit infants and those who had not, although because of the large number of tied values the median for the junior pupils who received free fruit as infants appeared to be lower (1.5 portions/d) than for those who did not receive free fruit (2 portions/ d). Medians at the school level were 1.5 and 1.75 portions/d, respectively, and there were no statistically significant differences when analysed at the level of schools.

If fruit juice was excluded, $17 \%$ of infants in schools in the NSFS reported not having any fruit on the day of the survey, compared with $27 \%$ of infants in control schools $\left(\chi^{2}=12.04\right.$, $P=0.001)$, and the differences between the distributions of the number of portions were again significant (Kolmogorov-Smirnov two-sample test, $P=0 \cdot 019$ ). Amongst the junior pupils, a higher percentage who had received fruit as infants reported consuming no fruit (32) compared with pupils in controls schools (26), but neither $\chi^{2}$ nor Kolmogorov-Smirnov tests revealed statistically significant differences between those who had received free fruit as infants and those who had not.

The weight of fruit consumed by each child $(\mathrm{g} / \mathrm{d})$ was estimated by summing the products of the reported number of portions
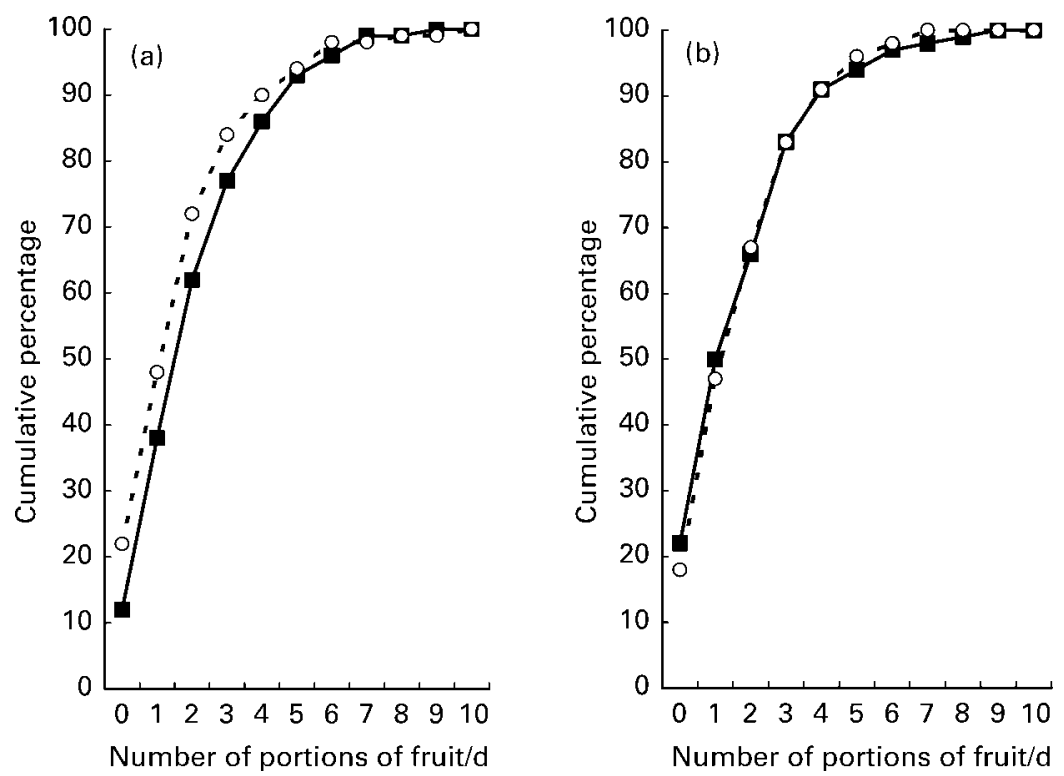

Fig. 1. Cumulative percentages of the number of portions of fruit (including fruit juice) consumed daily in 1492 primary school pupils in Southeast England, according to year group (infant, (a) or junior, (b)) and whether they had received free fruit at school (- - -) or not (--O--). 
of each type of fruit eaten by the average portion size (calculated from National Diet and Nutrition Survey data for 4-6- and 7-10year-olds; Gregory \& Lowe, 2000). Table 1 shows the daily median (interquartile range) total fruit consumption and fruit consumption excluding fruit juice according to year group (infant or junior) and receipt of free fruit. Infant pupils receiving free fruit at school had a significantly higher median consumption of total fruit $(150 \mathrm{~g} / \mathrm{d})$ than pupils in the control schools $(130 \mathrm{~g} / \mathrm{d})$, a difference of $20 \mathrm{~g} / \mathrm{d}$. The difference was substantially higher $(50 \mathrm{~g} / \mathrm{d})$ if fruit juice was not included $(117 \mathrm{~g} / \mathrm{d}$ and $67 \mathrm{~g} / \mathrm{d}$, respectively). There were no significant differences in median fruit consumption (with or without fruit juice) in the junior school pupils according to whether or not they had received free fruit at school as infants. There were no differences in median fruit consumption (with or without fruit juice) between infant and junior school pupils attending schools in the NSFS, but juniors had significantly higher levels of consumption than did infants in schools not in the scheme. Statistically significant differences in consumption were not evident at the school level because the number of observations was so small and the power substantially reduced, despite the median differences in consumption calculated at the school level being very similar to the values based on observations collected at the individual level.

A total of 107 questionnaires (7.2\%) were completed for weekend rather than week days. As the aim of the present study was to assess overall fruit consumption, these data were included in results shown in Tables 1 and 2 . When they were excluded from the analysis, the findings were essentially unchanged. There were too few observations for weekend days within subgroups (infant $v$. junior, in NSFS or not) to justify calculation of medians and associated statistics based on weighted observations.

Table 2 shows that $9 \%$ of parents of infants who received free school fruit were not aware that their child did so; conversely, $40 \%$ of parents of junior children who used to receive free fruit at school were not aware that their child no longer did so; and $10 \%$ of junior school parents believed that their child currently received free school fruit even though they never had. There was no association between children's median fruit consumption (g/d) and parents' beliefs about whether or not their child was receiving free school fruit, taking into account year group and actual receipt of free school fruit.

The parents of 483 infant pupils who believed (correctly) that their child was receiving free school fruit were asked a question about whether or not they had changed the amount of fruit they gave to their child. The majority $(394(82 \%))$ reported not having changed the amount of fruit they provided for their child; fifty-three $(11 \%)$ said that they provided more and fifteen (3\%) said that they provided less. The remaining 21 (4\%) were unable to say whether there had been any change. There were no statistically significant differences between the reported amounts of total fruit consumed and the reported changes in the level of fruit provided.

\section{Discussion}

The present study was a small preliminary assessment of the influence of the NSFS on fruit consumption in primary school pupils.

The schools selected were in areas in the bottom fifth of the distribution of the IMD (Department of Transport, 2000). These areas were chosen because it was likely that the scheme would show a higher proportionate increase in fruit consumption than in more affluent areas in which fruit consumption is higher (Gregory \& Lowe, 2000). They were also typical of the areas targeted for the pilot of the NSFS.

The pupil response rates were lower than anticipated. This may partly reflect the choice of areas, as response rates tend to be lower in low-income households. Nevertheless, the results from the present study provide a useful early assessment of the effects of the NSFS. If there is a bias in the result, it is likely to overstate the effect of the intervention, as parents who did not respond are less likely to have nutrition as a priority and hence may serve their children less fruit at home.

\section{Infants}

The results show that median total fruit consumption was higher amongst infant school children attending schools participating in the NSFS. Fruit consumption not including fruit juice, a better reflection of the effects of the scheme, was $50 \mathrm{~g} / \mathrm{d}$ greater. This is equivalent to two-thirds of a small apple. It is reasonable to attribute this difference to the effects of the scheme.

The smaller $(20 \mathrm{~g} / \mathrm{d})$ difference in total fruit consumption between groups of pupils at infant schools inside or outside the scheme is explained by differences in the amounts of fruit juice being consumed. It is possible that differences in fruit juice consumption existed before the start of the NSFS. Although a small percentage (14) of parents said that they had changed the provision of fruit to their children at home as a result of their participation in the NSFS, there was no evidence from the present study to suggest that the levels of fruit consumption varied according to the reported changes in behaviour.

Table 1. Total fruit consumption and fruit consumption excluding fruit juice ( $\mathrm{g} / \mathrm{d})$ in 1492 primary school pupils in Southeast England, according to year group (infant or junior) and whether or not they had received free fruit at school

(Values are medians, with interquartile range given in parentheses)

\begin{tabular}{|c|c|c|c|c|c|c|}
\hline \multirow[b]{2}{*}{ Received free fruit } & \multicolumn{2}{|c|}{ Infant } & \multicolumn{2}{|c|}{ Junior } & \multicolumn{2}{|c|}{$P^{*}$ (infant $v$. junior) } \\
\hline & Yes & No & Yes & No & Yes & No \\
\hline$n$ & 534 & 376 & 202 & 380 & & \\
\hline Total fruit (including juice) $(\mathrm{g} / \mathrm{d}$ ) & $150(67-286)$ & $130(65-220)$ & $165(75-325)$ & $161(77-315)$ & 0.843 & 0.000 \\
\hline$P^{*}$ & 0.000 & & 0.878 & & & \\
\hline Total fruit (excluding juice) $(\mathrm{g} / \mathrm{d})$ & $117(65-181)$ & $67(0-151)$ & $83(0-166)$ & $86(0-166)$ & 0.169 & 0.001 \\
\hline$P^{*}$ & 0.000 & & 0.336 & & & \\
\hline
\end{tabular}

*Based on Mann-Whitney test. 
Table 2. Parents' knowledge of child's current receipt of free school fruit, for $1473^{\star}$ primary school pupils in Southeast England, according to year group (infant or junior) and whether or not they had received free fruit at school

\begin{tabular}{lccccc}
\hline & \multicolumn{2}{c}{ Infant } & & \multicolumn{2}{c}{ Junior } \\
\cline { 2 - 3 } \cline { 5 - 6 } Received free fruit & Yes & No & & Yes & No \\
\hline$n$ & 530 & 368 & & 199 & 376 \\
$\begin{array}{l}\text { Yes, receives fruit } \\
n\end{array}$ & 483 & 31 & & 62 & 39 \\
$\%$ & 91.1 & 8.4 & & 31.2 & 10.4 \\
$\begin{array}{l}\text { No, does not receive fruit } \\
n\end{array}$ & 25 & 291 & & 119 & 314 \\
$\%$ & 4.7 & 79.1 & & 59.8 & 83.5 \\
$\begin{array}{l}\text { Don't know } \\
n\end{array}$ & 22 & 46 & & 18 & 23 \\
$\%$ & 4.2 & 12.5 & 9.0 & 6.1 \\
\hline
\end{tabular}

${ }^{*}$ Nineteen parents did not complete this question.

Several potential sources of bias could confound the results. First, the cooperation rates varied between schools. Rates were higher in areas not participating in the NSFS and in less deprived areas (based on the IMD scores). There were, however, no differences in fruit consumption according to the area IMD scores. Amongst the infants, there was a higher proportion of manual social class families in the schools not in the scheme (48\% compared with $35 \%$ ) and a lower proportion of unemployed families $(22 \%$ v. $31 \%$; $\left.\chi^{2}=15 \cdot 56, P=0 \cdot 001\right)$. It could be argued that poor numeracy and literacy skills in lower social class or unemployed parents would yield lower estimates of fruit consumption. The observed social class distributions in the two groups might have balanced out such biases. Moreover, there were no apparent trends in consumption by social class. The accuracy of the completed questionnaire would in part have been affected by the ability of the child to report correctly to their parents what they consumed while away from home. It would have been preferable if the consumption of fruit at school had been reported by someone present in the school. Errors in relation to the children's reporting would, however, have been likely to affect all of the reporting equally. Children from Indian and Pakistani backgrounds ate more fruit than white British children, but when the results were analysed for white British children alone they remained statistically significant. Excluding data for weekend days (7\%) had only a minor effect on the results. Moreover, it can be argued that including weekend days in the analysis shows that the scheme is having an effect overall and is not being diluted by the lack of free fruit at the weekends.

In the absence of longitudinal data, it is not unreasonable to conclude from the present cross-sectional study that the NSFS was having a significant influence in raising the level of fruit consumption in infant school pupils.

\section{Juniors}

Total fruit consumption (including fruit juice) was higher in the juniors than in the infants (Table 1). There was no evidence to suggest, however, that the provision of free fruit to infants affected their fruit consumption as junior school pupils. Median consumption of fruit by junior school pupils did not differ according to whether or not they had received free fruit as infants. It should be noted that the Year 4 pupils received free fruit for less than 1 year in infant school. This may have been too short to produce an effect in junior school pupils. However, separate analysis for Years 3 and 4 did not yield an alternative interpretation. Thus, there was no apparent effect on fruit consumption in those junior school pupils in Year 3 who had received free fruit for over 1 year as infants. The higher fruit consumption of junior pupils compared with infant pupils not receiving fruit is part of the normal increase in food consumption that occurs with age (Gregory \& Lowe, 2000). The fruit given to infants can thus be regarded as an early stimulus to consumption that does not seem to have had a lasting effect.

The potential biases mentioned in relation to the infant school pupils also apply to the junior school pupils. As with the infants, however, there were no confounding effects that could explain the lack of difference in fruit consumption between the junior school pupils who had attended schools in the pilot NSFS and those who had not.

\section{Comment}

There are no published studies evaluating the effect of the NSFS on fruit consumption. Two recent studies have measured fruit intake in English school children aged 3 to 7 years (Adamson et al. 2003; JE Cade, L Frear and DC Greenwood, unpublished results). Both of these studies used tick lists to record food consumption, with observers recording food intake during the school day. The reported mean number of fruit portions consumed daily was 2 (Adamson et al. 2003) and 2.4 (JE Cade, L Frear and DC Greenwood, unpublished results). In the present project, the mean consumption was $2 \cdot 1$ portions/d. This would suggest that the modified version of the FAST questionnaire used in the present study was performing similarly to the original. Good agreement between the tick list and the food frequency questionnaire data in the present study supports this view.

The main aim of the NSFS pilot scheme was to examine the practicalities of its operation before launching it nationwide (Department of Health, 2003b), ensuring that fruit actually reaches the child's hand. In these terms, the pilot scheme is seen as being very successful by the Department of Health. As a result, the scheme has been extended to other parts of England sooner than previously anticipated (Department of Health, 2003a).

Two reviews (Perez-Rodrigo \& Aranceta, 2001; French \& Stables, 2003) and recent research (Lowe et al. 2004; Perry et al. 2004) suggest that the most successful schemes to increase fruit and vegetable consumption in children have used a multicomponent approach. The NSFS has one primary component, the actual provision of free fruit. This is intended to be set in a context of activities to promote fruit consumption (Department of Health, 2003a), including: reward schemes for eating fruit; fruit-only tuck shops (in-school kiosks selling snacks and confectionery); numeracy, literacy and health sessions in the curriculum; parental involvement. While the direct provision of fruit is clearly effective in the short term in increasing children's fruit consumption, as evidenced by the present findings and the subscription schemes in Norway (Norwegian Directorate of Health and Social Affairs, 2004) and Denmark (Eriksen et al. 2003), it appears to be less successful in sustaining longer-term (1-2 year) changes in the absence of a coherent programme of support. In the present study, it is not known what proportion of schools implemented the recommended supporting activities and to what extent they may have had an effect on the levels 
of consumption. The apparent lack of effect of the scheme on junior pupils' fruit consumption does not necessarily mean that benefits in later life will not be shown. It would be appropriate, however, within the context of the NSFS, to consider how other aspects of nutrition promotion and integration of nutrition into the primary school curriculum might need to be presented in a more systematic way in order to promote a more sustainable outcome.

\section{Acknowledgement}

The present work was funded by and carried out at King's College London.

\section{References}

Adamson AJ, Griffiths JM, Carlin LE, Barton KL, Wriecken WL, Matthews JNS \& Mathers JC (2003) FAST: Food Assessment in Schools Tool. Proc Nutr Soc 62, 84A.

Department of Health (2003a) National Schools Fruit Scheme. http:// www.doh.gov.uk/fiveaday/schoolfruit.htm

Department of Health (2003b) The National School Fruit Scheme, evaluation summary. http://www.doh.gov.uk/fiveaday/pdfs/ nationalfruitsummary.pdf

Department of Health (2003c) FACET questionnaire. http://www.doh.gov. uk/fiveaday/pdfs/facetquestionnaire.pdf

Department of Transport (2000) Local government and the regions. Indices of deprivation 2000. http://www.neighbourhood.statistics.gov.uk/ reports/eng/tableviewer/wdsview/dispviewp.asp?dsid $=474$
Eriksen K, Haraldsdottir J, Pederson R \& Flyger HV (2003) Effect of a fruit and vegetable subscription in Danish schools. Public Health Nutr 6, 57-63.

French SA \& Stables G (2003) Environmental interventions to promote vegetable and fruit consumption among youth in school settings. Prev Med 37, 593-610.

Gregory J \& Lowe S (2000) National Diet and Nutrition Survey: Young People aged 4 to 18 Years, vol. 1. London: The Stationery Office.

Lowe CF, Horne PJ, Tapper K, Bowdery M \& Egerton C (2004) Effects of a peer modelling and rewards-based intervention to increase fruit and vegetable consumption in children. Eur J Clin Nutr 58, 510-522.

Nishida C, Shetty P \& Uauy R (2004) Introduction. Public Health Nutr 7, 99-100.

New Opportunities Fund (2005) Grants awarded. http://www.nof.org.uk Norwegian Directorate of Health and Social Affairs (2004) Norwegian school fruit scheme. http://www.skolefrukt.no/pdf/skolefrukt_eng.pdf

Perez-Rodrigo C \& Aranceta J (2001) School-based nutrition education; lessons learned and new perspectives. Public Health Nutr 4, 131-139.

Perry CL, Bishop DB, Taylor GL, Davis M, Story M, Gray C, Bishop SC, Mays RA, Lytle LA \& Harnack L (2004) A randomized school trial of environmental strategies to encourage fruit and vegetable consumption among children. Health Educ Behav 31, 65-76.

Thompson B, Demark-Wahnefried W, Taylor G, et al. (1999) Baseline fruit and vegetable intake among adults in seven 5 a day study centers located in diverse geographic areas. J Am Diet Assoc 99, 1241-1248.

Williams C \& Marmot M (1997) Changing rationales, consistent advice: dietary recommendations on vegetable and fruit. In National Heart Forum. Preventing Coronary Heart Disease, The Role of Antioxidants, Vegetables and Fruit, pp. 49-62 [L Rogers and I Sharp, editors]. London: The Stationery Office.

World Health Organization (2003) Diet, Nutrition and the Prevention of Chronic Diseases. Report of a Joint WHO/FAO Expert Consultation. Technical Report Series no. 916. Geneva: WHO. 